\title{
This has been a real uphill battle : Three organisations for the adoption of Last Planner System
}

\section{Mäki, Tarja}

2020-02

Mäki , T , Kerosuo , H \& Koskenvesa , A 2020 , ' This has been a real uphill battle : Three organisations for the adoption of Last Planner System ' , Canadian Journal of Civil Engineering , vol. 47 , no. 2 , pp. 109-117 . https://doi.org/10.1139/cjce-2018-0405

http://hdl.handle.net/10138/335187

https://doi.org/10.1139/cjce-2018-0405

unspecified

acceptedVersion

Downloaded from Helda, University of Helsinki institutional repository.

This is an electronic reprint of the original article.

This reprint may differ from the original in pagination and typographic detail.

Please cite the original version. 
Full title of the paper:

This has been a real uphill battle...

Three organisations for the adoption of Last Planner System

\section{Authors}

Tarja Mäki. Hannele Kerosuo, Anssi Koskenvesa

\section{Affiliation and address at the time of the study}

Name: $\quad$ Tarja Mäki ${ }^{1}$

Affiliation: University of Helsinki

Faculty of Educational Sciences, Department of Education/CRADLE

Address: Siltavuorenpenger 1A / P.O.Box 9

00014 University of Helsinki, Finland

Name: Hannele Kerosuo ${ }^{2}$

Affiliation: University of Helsinki

Faculty of Educational Sciences, Department of Education/CRADLE

Address: Siltavuorenpenger 1A / P.O.Box 9

00014 University of Helsinki, Finland

Name: $\quad$ Anssi Koskenvesa ${ }^{3}$

Affiliation: Mittaviiva Oy

Address: Lars Sonckin kaari 10

02600 Espoo, Finland

\section{Contact information of the corresponding author}

Name: $\quad$ Tarja Mäki

Email tarja.maki@mittaviiva.fi

\footnotetext{
1 Tarja Mäki, as corresponding author, is responsible for the article as a whole and especially the parts considering research on the construction industry and lean construction.

${ }^{2}$ Hannele Kerosuo, as second author, is responsible for the parts of the article considering organisational learning and research methodology.

${ }^{3}$ Anssi Koskenvesa, as third author, had an active role in conducting the research project and especially organising the training sessions in the organisations.
} 
This has been a real uphill battle...

Three organisations for the adoption of the Last Planner System

\begin{abstract}
This study examines the learning processes of the adoption of the Last Planner System (LPS) and mechanisms of learning indicating the successes and failures of their establishment in three organisations. The organisations under study are a public building agency, an engineering office, and a construction company. One practice-based methodology of organisational learning based on the theory of expansive learning (Engeström \& Sannino 2010) was applied in the analysis. The ethnographic research data included the observation of LPS adoption processes and the interviews of the participants. This study links the epistemic learning actions of the theory of expansive learning to the adoption process of LPS. It also reveals the mechanisms that indicate the success or failure of the adoption process. A successful adoption process seems to require strong ownership, enough time, resources and opportunities for learning together in practical project work, and the combination of top-down and bottom-up approaches.
\end{abstract}

Keywords: Last Planner System, adoption, learning, construction, expansive learning

\title{
1 INTRODUCTION
}

Lean production is considered to be the superior production template for the construction industry (Bertelsen \& Koskela 2005). In particular, the Last Planner System (LPS) has been widely used in the construction field (Priven et al. 2016). LPS is a collaborative planning system for project management. It aims to increase work plan predictability with several steps of scheduling: milestone planning, phase planning, look-ahead planning and weekly work planning. The predictability is measured with percent plan complete rate (PPC). (Fernandez-Solis et al. 2013; Koskela et al. 2010)

LPS has shown improvements in project organisations' connectivity (Priven \& Sacks 2015). It has highlighted the effects of using LPS in improving production in construction projects as well as their positive influence on the organisation in charge (Castillo et al. 2016). LPS improves workflow reliability by shielding short-term work from the uncertainty surrounding downstream processes (Ballard \& Howell 1994). It is generally adopted by multiple companies working together on a construction project to achieve gains in efficiency (Tillmann \& Sargent 2016).

Despite the undeniable benefits, the adoption of new methods is always a complex process. Numerous practical matters, such as the lack of instructions and best practices may disturb the adoption processes (Arayici et al. 2011). The managers leading the LPS adoption processes have been reported as facing resistance from clients and subcontractors and lack of support from the organisations (Fernandez-Solis et al. 2013). According to Perez and Ghosh (2018), project teams need an incremental implementation strategy and a LPS champion to widen and maintain the learned practices. The fragmented leadership is seen as a hindrance to the process. The construction organisations are often based on a hierarchical management model (Chioccio et al. 2011). Bottom-up processes instead of top-down approaches may be better to motivate and to engage employees in the adoption processes (Arayici et al. 2011). Decision-making and procedures may proceed asynchronously and in different operating environments, and managing them can become challenging (Engeström et al. 2007). The employees may hold on to old working procedures to keep on working within their comfort zone (Whyte \& Lobo 2010).

Some previous studies have addressed the topic of learning connected to LPS system. The focus 
of Koskela et al. (2010) is on the evaluation of plans. Arayci et al. (2011) note that the implementation of new tools involves a high amount of learning on the level of workflows. Members of staff are required to reinvent the work processes and to align old methods with the entire context of work. Kalsaas (2012) examines LPS in the light of the learning processes drawing from Kolb's experiential learning theory (Kolb 1984) and workplace learning. In spite of the advantages of experiential learning to successful adoption of LPS system, Kalsaas sees some limitations regarding the generation of changes to the organizational level of the engineering and architectural work as well as challenges brought about the complexities deriving from the context of construction industry. Kolb's theory has also been criticized for being epistemologically problematic. Especially, the model of learning is generalized on a historically very specific and unilateral mode of experience. (Miettinen 2000)

This research attempts to increase the knowledge about the adoption process of LPS as a learning process on the operational and organisational levels in practice by drawing from different theoretical basis. The theory of expansive learning (Engeström 1987) is applied as a framework for analysing the processes of adoption in three organisations. The theory of expansive learning and its respective methodology provide theoretical tools and methods for analysing processes of learning on different levels of an organization in its historically evolved context. The expansive learning shows, how the learning of LPS system emerges during the adoption process. (Engeström \& Sannino 2010)

The researchers examined the learning processes of adopting LPS to find the mechanisms that indicate successes and failures in their establishment. These are understood as implications of organisational learning or lack of it. The companies participating the study were a public building agency, an engineering office, and a construction company. The researchers used ethnographic methods in their empirical research into the adoption process.

\section{ORGANISATIONAL LEARNING AND THE ADOPTION OF NEW WORKING METHODS}

There is no unified theory or single definition of organisational learning. According to EasterbySmith and Lyles (2011), the reason for this may be caused by different disciplinary-based definitions as well as different ontologies and practices. However, most actors agree that "organisations have knowledge, do learn over time, and consider their knowledge base and social capital as valuable assets" (p. 1). Fiol and Lyles (1985) emphasize organisational learning as a process of changing organisational actions through new knowledge and understanding. The outcomes of learning can be detected as new operational and organisational knowledge, competency and understanding in an organisation.

The adoption of new methods is not considered to be a distinct research subject in the literature of organisational learning. In the early days, learning was primarily considered to be a cognitive issue, whereas adaptation was a secondary behavioural issue taking the level of adopting routines (Fiol \& Lyles 1985). Fiol and Lyles show that the vocabulary is interchangeable between learning and adaptation. Learning is called adaptation in some and action in other sections of the literature. In this study, learning is seen as an elementary process in the adoption of new methods. The distinction between learning and behaviour is made but learning is understood to take place in actions.

The importance of the social and cultural context has been acknowledged in project-based organisations (Bresnen 1990; Swan et al. 2010). Siriwardena (2015) has recently reviewed the elements, mechanisms and techniques of organisational learning in the construction industry. Anheim (2003/Siriwardena 2015) states that the project-based nature of construction is both an advantage and an obstacle. The nature of complexity supports the learning of autonomous teams, which is an important aspect of learning in project work. However, project-based contexts 
pose also limits on learning from one project to another. (Anheim (2003/Siriwardena 2015) In previous research, it has been specified that these obstacles emerge between learning in single projects and in a focal organisation (Prencipe \& Tell 2001; Chan et al. 2005; Swan et al. 2010).

According to Swan et al. (2010), the accumulation of experience is the most typical type of learning among individuals and within project-based organisations. Moreover, they suggest welldeveloped project management competencies increase the accumulation of experience in project-based organisations. Compared to Siriwardana's (2015) study examining an entire construction project, only the adoptation phase has been investigated in this study. Learning is situated in local processes within and between managerial and operational levels of projects.

Practice-based theories provide an alternative approach to traditional organisational learning theory for studying the actual work practices in projects (Kokkonen \& Alin 2015). These approaches have introduced an epistemology for studying practices, often hidden in studies of organisations and organisational learning (Corradi et al. 2010). It is generally accepted that the focus of practice theories is on what humans actually do when they practice various tasks in organisations (Miettinen et al. 2009), although, no single but many practice-based theories deriving from different theoretical origins exist (Nicolini 2012). According to Miettinen et al. (2009), the embodied nature of practice, knowing how to act and use artefacts are also interests of practice theories.

Over the years, practice-based approaches of learning have received considerable criticism for being ambiguous (Corradi et al. 2010) and unclear in studies concerning the construction industry (Kokkonen \& Alin 2015). For instance, the criticism on the use of the term 'community' in the popular community of practice approach (Wenger 1998) has led to proposals to reverse the term into practices of community (Gherardi et al. 1998). In the next section, we will introduce the developmental methodology based on the theory of expansive learning (Engeström 1987) for studying learning in the adoption of LPS.

\section{THE EXPANSIVE DEVELOPMENTAL METHODOLOGY FOR STUDYING THE ADOPTION OF LPS}

The theory of expansive learning and its methodology for developmental research (Engeström 1987) offer specific activity-theoretical concepts for studying embedded processes of learning in practice. The focus of expansive learning is on learning the content of which is not known beforehand (Engeström \& Sannino 2010). The theory of expansive learning is based on culturalhistorical activity theory deriving from Russian cultural psychology (Engeström 1987). The main concepts of the theory relevant to this study are the object-oriented activity system, the process of expansive learning and the epistemic learning actions.

The object-oriented activity system theorized by Engeström is one of the main concepts for studying processes of expansive learning. The mediating elements of an activity system are the subject, instruments, object, rules, community, and division of labour. (Engeström 1987) An activity is motivated by a collective object and there is no object-less activity (Leont'ev 1978). Engeström (1995) has clarified that something culturally given is simultaneously created with something constituted by subjects on an activity. Adler (2005) emphasized, goals, purposes or ideas people have in their minds are also reflected on objects of activity. However, an object can only be partly shared within and between activity systems because different subjects have different views about it (Miettinen et al. 2012).

Activity systems are realized in actions and operations of individual subjects and groups embedded in a network of other activities (Miettinen et al. 2012). Transformation of an activity system is triggered by contradictions that are manifested in several forms on the level of actions and operations of a work activity (Engeström \& Sannino 2010). The examination of contradictions 
would require a historical analysis of their evolving (Kerosuo 2006), but the focus of this study is on the effects of contradictions on the level of epistemic actions, so the contradictions are not analysed here.

Engeström and Sannino (2010) have defined seven types of epistemic learning actions These epistemic learning actions enable the analysis of the learning mechanisms in processes of expansive learning. Figure 1 depicts the cycle of expansive learning (Engeström 1987) as a sequence of epistemic learning actions adapted from Engeström and Sannino $(2010,8)$.

The sequence of epistemic learning actions represents an ideal model of how the process of expansive learning can proceed. In this study, researchers applied the ideal model of epistemic learning actions in the analysis of learning processes during the adoption of LPS. But epistemic learning actions do not necessarily proceed as presented in the ideal model and incomplete cyclicity may emerge (Engeström et al. 2013).
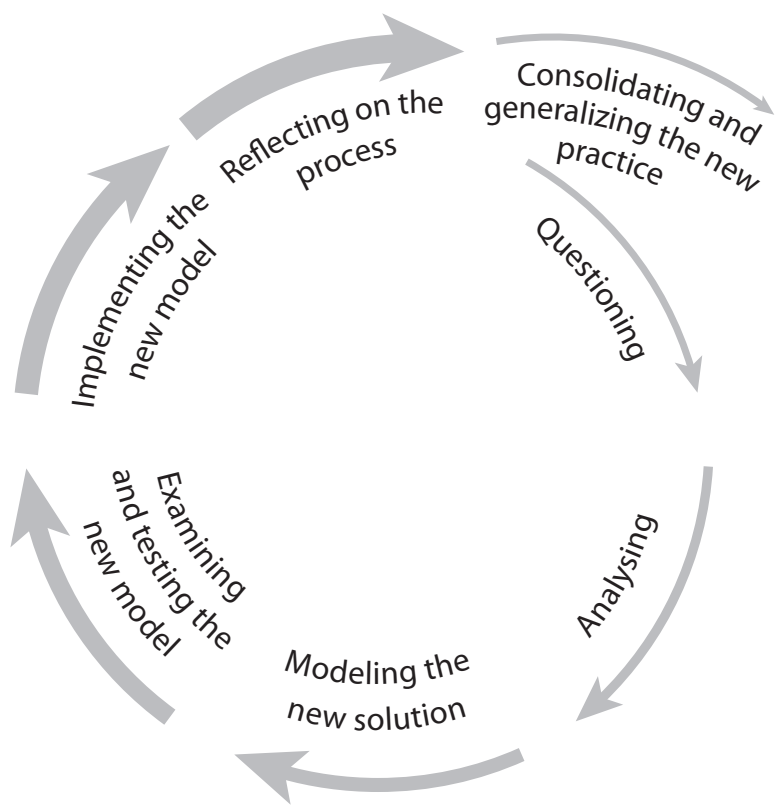

Figure 1. The sequence of learning actions in an expansive learning cycle (adapted from Engeström \& Sannino 2010, 8)

Young (2001) has criticized the theory of expansive learning for enhancing incidental learning. According to Young, the access to knowledge is problematic when the content of learning is considered unknown beforehand. What is to be learnt is co-constructed by the subjects when they are involved in the development of their activities (Engeström \& Sannino 2010). Still, the content of learning is not entirely unknown or incidental in this study. The processes and tools applied in LPS, such as a master plan, weekly plan, look-ahead plan, make-ready process or PPC rate, are already known before the adoption process begins and different preconditions and other project activities frame the operations and learning in the project.

LPS is a collaborative planning system that involves several groups of construction professionals for scheduling a construction project. LPS is a process that comprised of ideal phases from the preparation of a master schedule to monitoring of the execution of the tasks (PPC) (Koskela et al. 2010). In real-life projects, it is often implemented only partly (Priven \& Sacks 2016). In spite of that LPS process gathers different project partners to plan together, share their knowledge and create a common schedule for projects. The schedule is followed and its deviations are weekly 
analysed. The idea is to learn from the analysis for the planning of the next phase in a schedule.

The process of expansive learning (Engeström 1987) is also descripted as a process that has ideal steps, a sequence of learning actions, from questioning to consolidation and generalization (Engeström \& Sannino 2010). As the process of LPS, also the process of expansive learning is interrupted, paused or some steps are disregarded in the real-life projects. The engagement of actors at the level of practices is considered essential also in the expansive developmental methodology (e.g. Engeström, Lompcher \& Ruckriem 2005).

From the perspective of expansive learning, LPS is at the same time an object of adoption and a tool for managers and employees in a construction project (Kerosuo \& Engeström 2003). It changes the participants' division of responsibilities. During the adoption of LPS new ways of working and new rules are created. Compared to the prevailing practices employees are involved in the planning of their work schedule with each other and other parties. This means that their object of work activity expands in activity-theoretical terms. The community of production planning also expands compared to previous situation.

\section{METHODS AND DATA}

In expansive developmental research (Engeström et al. 2005), researchers often collect data by adapting ethnographic research methods such as participatory observation (i.e. Ellen 1984; Fetterman 2010). The ethnographic case study method was used to collect the ethnographic data in three organizations. An investigation can be described to be a case study if it involves ethnographic research in one or multiple locations (Ragin 1992). Three organizations were selected from construction industry to enable a comparison based on difference in size and intake in a building process. The organizations enrolled voluntarily to test LPS in practice with the purpose of adopting it.

The practical application of the theory of expansive learning called Developmental Work Research (DWR) was used to support the actual adoption processes in the three organizations. DWR is an interventionist method in which practitioners and researchers jointly investigate and analyse the data gathered from daily work in order to change their current work practices (e.g. Engeström et al. 2005). DWR is well known in educational sciences but there are few empirical studies examining the adoption phase of the process (Engeström et al. 2007). In this study, DWR provided a clear structure to the adoption process and framed the interaction between the researchers and practitioners. The method was re-configured to fit the contexts of each organisation in the planning phase of the adoption with the managers and contact persons in each organization.

The construction projects granted a possibility to get an in-depth view of the processes and mechanisms of learning during adoption. However, carrying out the fieldwork required continuously to make choices which subject and which project data were to be collected from (Marshall \& Bresnen 2013). The specific feature of the ethnographic method was that researchers constantly evaluated the subject of research and were prepared to change the emphasis of the study when observing the "traces" of developing and changing phenomena (Kerosuo 2006).

Ethnographic data collection methods were applied in observing adoption activity, workshops, and training events. The method of participatory observation was pursued to observe adoption of LPS closely in construction projects. Various meetings were also observed and recorded as part of the research data. The observational data offered a chance for the researchers to examine the progression of adoption, challenges and successes in the real-life situations. 
Semi-structured theme interviews and open interviews were used to study the participants' experiences and interpretations about the process of adoption and the training events (Rapley 2004). The interviewees were an eclectic group of construction business professionals. The interviews were mostly conducted as individual interviews. The final research data included observations of the pilot projects (13), interviews (20), meetings (14), training events (11), and steering group meetings (7).

The initial analysis of the interviews was based on theory-based content analysis (Braun \& Clark 2006). The activity-theoretical concepts constituted the theory base in use. The relevant parts of talk that related to the research themes were extracted from the interviews and patterns were created from the extracted themes. The quotations of extracts have been used as examples of the data.

The observation and interview data analysis were combined as a story for each organisation. Timelines were created to show how the processes proceeded temporally. Seven types of learning actions proposed by Engeström and Sannino (2010) were applied in analysing the mechanisms of the learning process for the adoption of LPS:

1) Questioning refers to criticizing or rejecting some aspects of the prevailing practice.

2) Analysing involves mental, discursive or practical transformation of the situation in order to find out causes or explanatory mechanisms

3) Modelling means constructing an explicit, simplified model of the new idea that offers a solution to the problematic situation

4) Examining the model to grasp its dynamics, potentials and limitations

5) Implementing the model by means of practical applications, enrichments, and conceptual extensions

6) Reflecting on and evaluating the process of expansive learning

7) Consolidating and generalising the outcomes into a new stable form of practice (p. 7).

The model of epistemic learning actions (Engeström and Sannino 2010) was considered as an analytical tool that can be used to depict he image of the overall process of the adoption process (Engeström et al. 2013). Developmental Work Research (DWR) guided the project work during the adoption processes. The ethnographic immersion to the field work was realized during the research work. Van Maanen (1988), among others, has pointed out some a priori theoretical orientations are difficult to avoid. Therefore, it is important to describe these unexpressed orientations (Delamont 2004). DWR may have worked as a priori orientation for the researchers in the conduction of the fieldwork.

In developmental research it is a challenge when researchers have double roles; being both researchers and interventionists or facilitators of development like in applied ethnography (Chambers 2000). In this study the authors tackled this problem with a division of labor. One of the three of us has mainly acted as a facilitator, another one mainly as an ethnographer in a researcher's role and the third one moving in-between these two roles. 
5 THREE ORGANISATIONS FOR THE ADOPTION OF THE LAST PLANNER SYSTEM

\subsection{Public building agency}

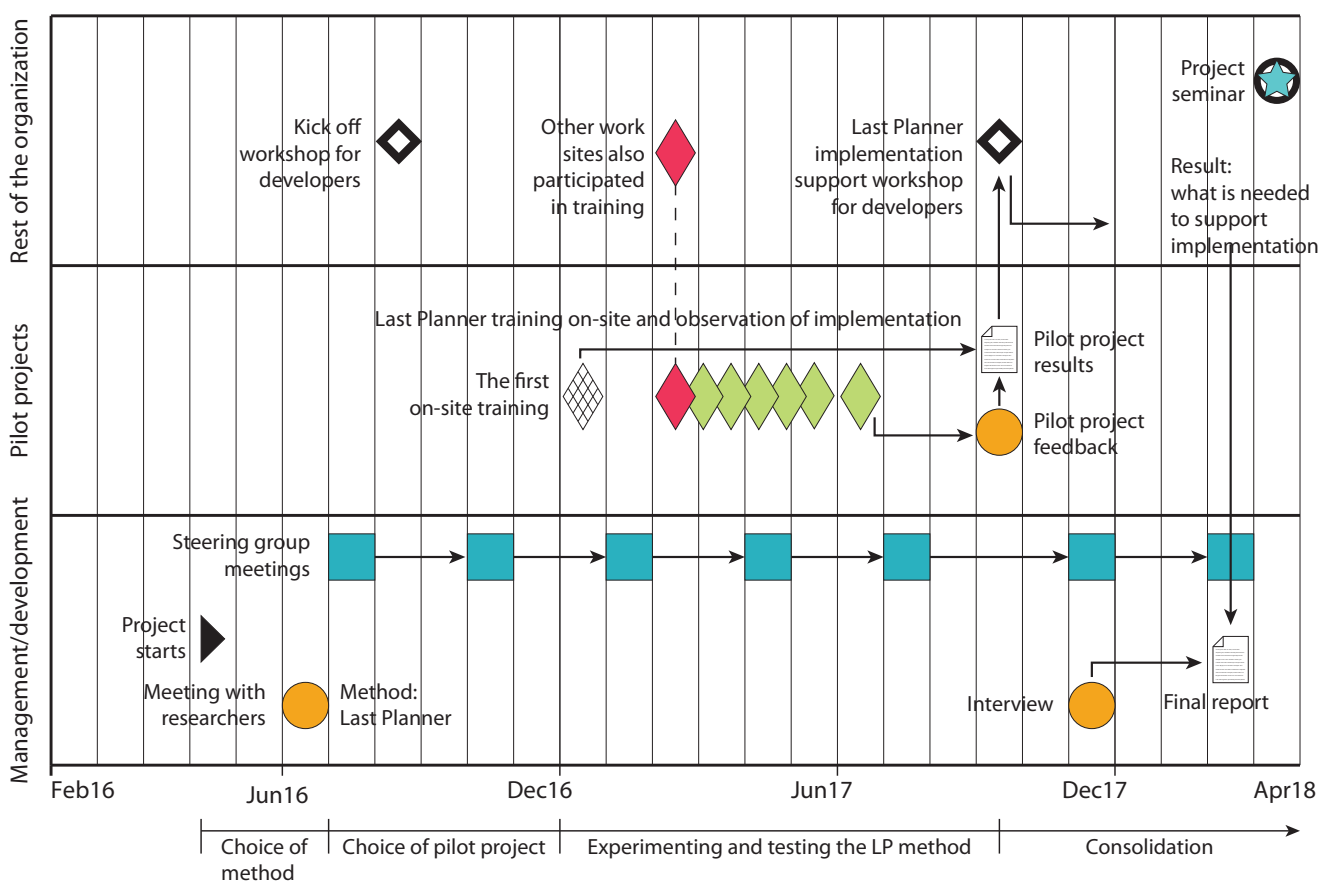

Figure 2. Time line of the adoption process in the public building agency.

The aim of the adoption of LPS was to have better schedule management in renovation projects. During the first steering group meeting, the representative of the organisation described the expectations for adoption of LPS in the following fashion:

The Last Planner method is to be tested. Construction work is to take as little time as possible [...]. Project manager

The adoption started with a workshop for the organisation's own staff. The workshop concerned the pilot project, LPS and scheduling challenges in the projects. The participants created an LPS schedule for the pilot project.

Two training sessions were organised for the construction site staff involved in the pilot project. The first session provided an overall view of the method, and the second started to adopt the method in the project. In the second session, the LPS phase schedule of the pilot project was composed. Contractors marked their tasks and obstacles in the schedule with coloured stickers. At the end of the training the schedule was evaluated to be realistic by the contractors.

After the training sessions, the construction site staff started holding weekly LPS meetings. In the meetings, the schedule was updated together to correspond to the actual situation. The meetings focused on the look-ahead and weekly planning. The PPC rate was not used.

At the end of the pilot project, the site personnel was asked to give some feedback of the LPS adoption process. According to them, a short, practical training session was necessary when LPS was introduced for the first time. The method was helpful in scheduling and it saved everyone's time in the project. The weekly meetings were better prepared when LPS was adopted. A digital, mobile tool would be useful to share the schedule within the project group.

After the pilot project, the public building agency arranged another workshop, where the manager of the pilot project shared his experiences to the other personnel. The participants were asked what they needed to adopt LPS in their own projects. The following requirements were 
brought up: all the project partners must be committed to the method. The use of LPS must be demanded through the contracts. Training and support is needed. The LPS facilitator must be a competent and proficient person.

At the end of the research project the representative of the public building agency were interviewed. The next steps for the adoption process were planned to be choosing new partners and projects, training them to use LPS, and setting up a steering group to promote to use of LPS through the organisation.

\subsection{Construction company}

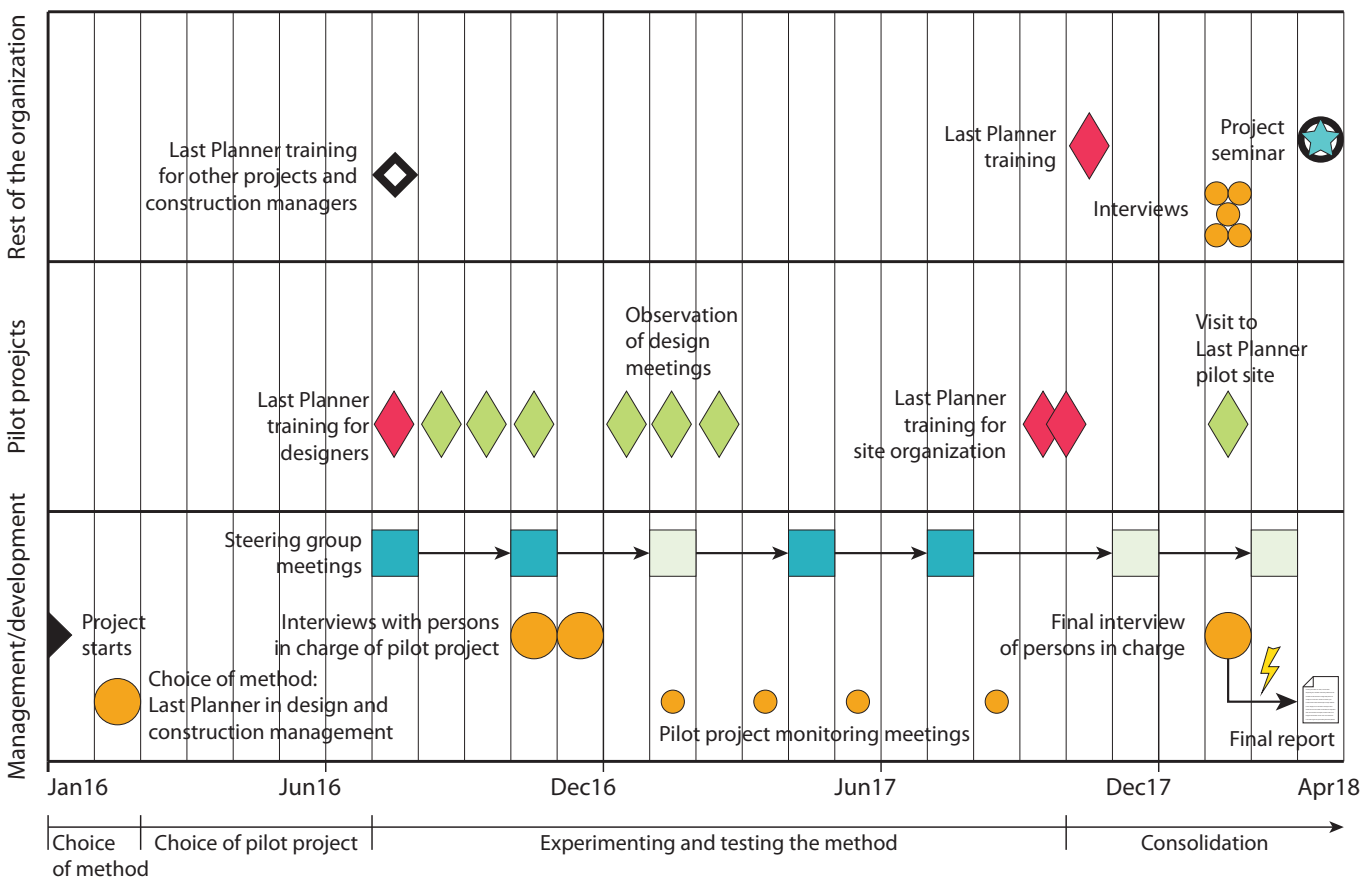

Figure 3. Time line of the adoption process in the construction company.

The representative of the company introduced the expectations of the adoption of LPS to be:

Productivity is what we are looking for. There is a lot of waste in our work. Last Planner combines collaboration and a sensible working method. Development director

As the first pilot project to adopt LPS was chosen, the company arranged training for the designers, project managers and site managers of the project. The development director described the enthusiasm of the project group after the training:

The entire design group met the Last Planner training with enthusiasm. They were pumped up about it. Development director

The researcher followed the adoption by participating in the design meetings once a month. In the meetings, the design group discussed the design tasks and prerequisites of them based on the phase schedule in the meetings. They agreed the tasks for the coming weeks together, but they did not utilize LPS tools in a systematic way. They tried to combine using LPS and the new software tool, but later they gave up using the tool as they felt it was too difficult. Either, PPC was not utilized during the pilot project.

After the design phase, the researcher interviewed the project manager and the main designer. The training was considered rewarding. LPS had improved the preparation of the design meetings and helped everyone in recounting schedule related matters. Another software tool to share designers' assignments would be needed. 
The researchers also interviewed the development personnel who was in charge of the LPS adoption. In the first interviews, the means to make LPS known to a wider group in the organisation were reviewed. The means were considered to be internal training, an intra-website and a new development program to support a wider use of Lean methods in the organisation. Also, it was considered important to create an introduction materials and tools to ease the use of LPS. LPS was expected to spread through pilot projects as people had good experiences with it. It was not seen that the development personnel would have an active role there, except organising the training for the project staff.

In the second interview, the aim was to find out how the adoption had proceeded in the organisation. The ideas that had come up in the previous interview were not carried out. This was partly due to lack of resources and that no-one had taken responsibility for the adoption. There were several other on-going developmental projects in the organisation, so there were insufficient resources to support the use of LPS.

\subsection{Engineering office}

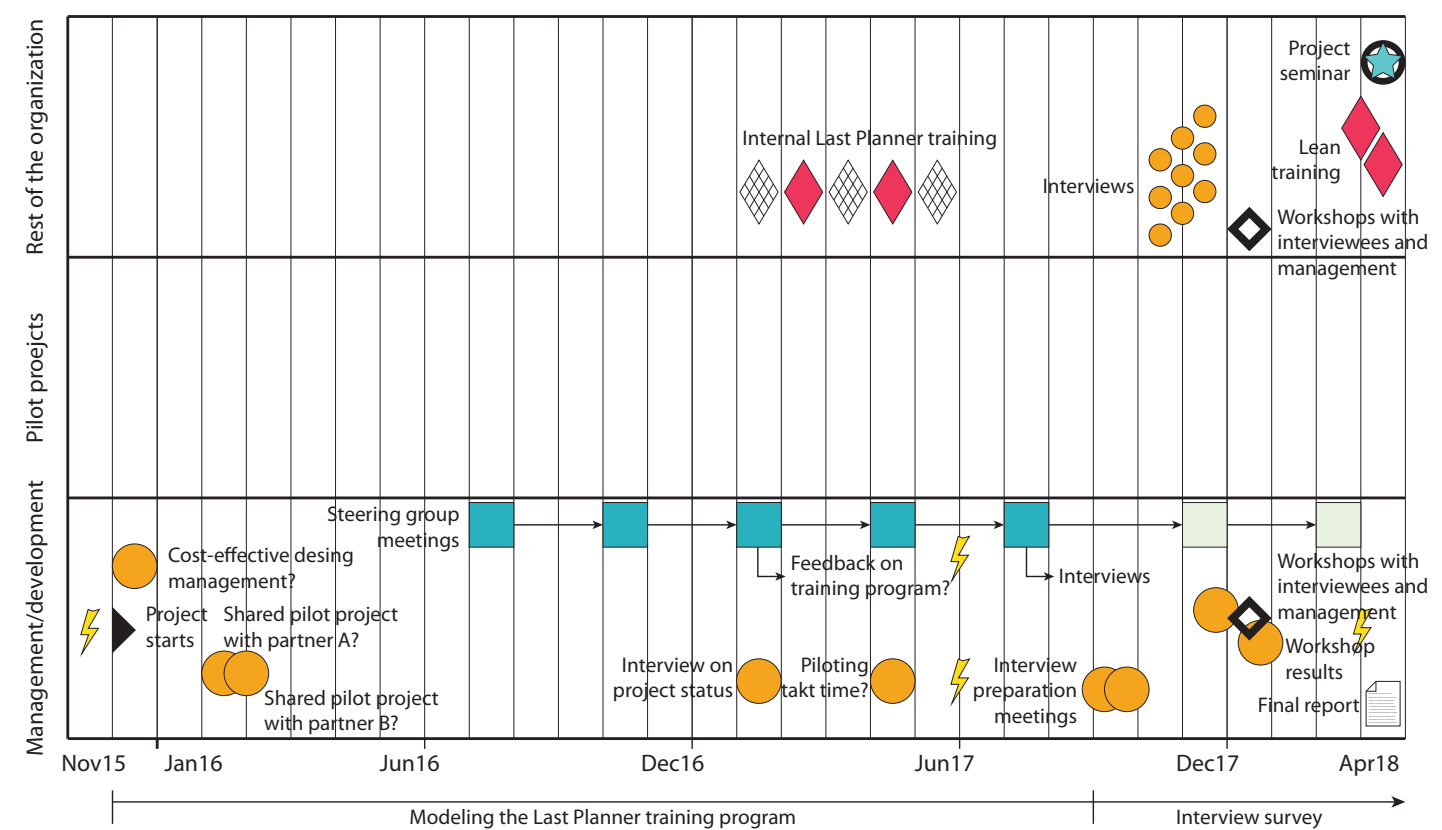

Figure 4.

Time line of the adoption process in the engineering office.

The CEO of the engineering office described the need for Lean methods the following way:

[LPS] hasn't been put into practice in any projects other than alliance projects. That is a problem. CEO

The organisation's objective was to shorten the construction time, save resources and expand Lean beyond alliance projects. The aim of all this was to gain a better competitive edge over competitors. To support LPS adoption the organisation developed an internal training program. The training program was put into practice, but it was realized afterwards that LPS were still not used in the projects. As the training did not produce the desired change, the management asked the researchers to find the obstacles of adoption. The researchers interviewed the personnel and examined why the methods were not adopted in practice. The following reasons came up.

Firstly, the interviewees did not see any urgent need for a change. They had a lot of projects to work with and the organisation did well in the competition. They saw a need for change, but that was more need to increase the feel of control of their daily work than to gain a better competitive edge. 
[Inefficiency] is not a critical problem. ... [but] the work could be more sensible. Hassle isn't sensible. Leader 1

The interviewees also criticized the fact that they were not heard in the planning of the training program. They felt that they would have had something to give, because they knew the project activity the best. There were also too many changes at the same time, which meant that ultimately none of the aspirations for change were taken seriously.

We were told what to do; there was no conversation about how we do things now and how we could improve it. Leader 1

The participants found it difficult to use the methods learnt in projects. They felt that they did not know the methods well enough. Adoption of new methods would have also been easier if the initiative for the change had come from the client. It was difficult to suggest any new methods for work in the designer's role.

The client had already ordered something and then one tries to launch a new procedure, it is difficult. Leader 3

One major idea in the training program had been that the trained personnel would spread their knowledge to the others and help them in their projects. According to the interviewees, this was an unrealistic idea. As each unit was responsible for its own profit, one did not tend to work for other projects.

How do I get him to do unpaid work? This idea is dead before it's born. Leader 1

The researchers presented the findings to the management. It was noted that there was a need to improve both communicating and defining the objective of the training, motivating the trainees, and re-planning the training program. The management decided to re-train a few experts in LPS. These experts would then train others and help the adoption of the methods in projects, but this time with more support from the organisation.

\section{THE DIFFERENCES AND SIMILARITIES OF ADOPTING LPS IN THE THREE ORGANISATIONS}

The three LPS adoption processes under study were apparently different. However, they also had something in common. Each process pursued better management and effectiveness through LPS. Every organisation started the adoption process with training. All the organisations adopted LPS only partly and as such it was known in previous projects.

As the differences between the adoption processes were several, only the central ones have been introduced in this article. The differences are the role in a construction project, an adoption approach and training and other support offered to the adoption process.

A fundamental difference between the organisations was the fact that the organizations had different roles in construction projects. This affected their ability to apply a new method in construction projects. The public building agency represented a client and had a chance to demand the use of LPS. The subcontractors utilised the new method eagerly, as it was a precondition for getting the job. The case of the engineering office was the opposite. Its personnel found it difficult to promote a new method to a client. In the case of the construction company, the method was tested only in the projects in which the company was responsible for the whole project, so it represented a client in the pilot projects.

All the organisations started the adoption with training. The public building agency offered on several step-by-step training sessions to the same group. The researchers followed up and supported their use of LPS in the weekly meetings. The construction company also trained their project staff in both the design and construction phases, but the overall support and follow-up 
was less in the pilot project. The engineering office relied exclusively on the training, but the actual training was short, and no other support or follow-up was offered.

The engineering office applied solely a top-down approach. The personnel were not involved in planning the training program. The requirement to join the adoption process came from the senior management. On the contrary, the construction company's management had a narrow role in planning or conducting the adoption of LPS. They started the adoption process by organising the training sessions and introducing the idea of LPS to the potential pilot projects, but afterwards, the pilot project personnel were responsible for adopting of the new working method. The public building agency combined bottom-up or top-down approaches: the management demanded the use of LPS in their projects. They organised LPS training sessions and other support during the adoption process. However, the project personnel had free hands to adapt the method as they see the best. After the pilot phase, another workshop was organised, in which the chief manager of the pilot project shared his experiences with the organisation's personnel how to adopt the method in practice.

According to this research, the best results seemed to be achieved by the strong role of the client in promoting the change, combination of the bottom-up or top-down approaches and supporting the adoption along the process with training sessions, practical tools, continuing follow-up and exchanging experiences.

\section{EXPANSIVE LEARNING CYCLES OF THREE ORGANISATIONS}

The cycle of expansive learning does not suggest "a universal formula of phases of stages" and hardly ever can one find a complete cycle in which the entire ideal-typical model has been followed (Engeström \& Sannino 2010, 7). The incomplete cycles may involve returns to previous stages or they can also form micro-cycles in which an ideal typical cycle is included within an entire cycle of expansive learning (Engeström et al. 2013).

The developmental projects in the current study represent mainly the incomplete cycles of experimenting and piloting of the new method. In the adoption process, there were interruptions, pauses and restarts as the process proceeded. All the adoption projects under study started with questioning and recognising the problems in current activities. However, the analysis of the current problems was completed at the general level and the participants moved quickly to choosing LPS to solve the problems. During the pilot projects, the method was tested and evaluated. However, the wider adoption in the whole organisation or consolidation of the new method was left in the design phase. The research project ended before a wider consolidation phase could be initiated.

The public building agency project started by recognising the problems in their current activity. A recognised challenge was weak scheduling management. Based on that knowledge, the management chose LPS to develop the scheduling in the projects. LPS was adopted as it stands.

After LPS was chosen, the training sessions were organised, and a pilot project was started on a construction site. The researchers followed one pilot project (arrow), but there were also three other pilot projects (dashed line) adopting LPS. The method was developed to fit the current activities during the pilot projects.

After the pilot projects, another workshop was arranged to share the experiences of using the method, the method evaluated, and ideas generated on how LPS could be used more extensively (curved arrow) in projects. The representatives of the public building agency also had views on how to support the adoption in the future, but there was not enough time to observe this in the current study. 
The LPS adoption was a step towards the strategic goals in the construction company. The current activities were not particularly questioned or analysed, but LPS was adopted in the form in which it had been known earlier. The adoption project proceeded strongly relying on the pilot projects. Several pilot projects commenced during the study. The people partaking in the pilot projects were responsible for the development of the method. The organisation's developmental staff had a narrow role in the adoption project. In the final interviews, ideas came up on how the use of the method could be supported to become a wider procedure in the organisation, but these measures were not yet launched and therefore could not be observed during the research project.

The senior management of the engineering office questioned their current procedures and brought up the need to develop the productivity of projects and collaboration. Systematic analysis on the causes of the problems was not performed under this study, but rather the organisation's internal training program was chosen as a solution. The training program was extensively introduced straightaway. The objective was to learn several Lean methods, e.g. LPS, and assign them to practical activity. As the methods were not transferred to practice after the training, it was decided to find out what had gone wrong with the adoption process. Based on the interview results, a new training program was being planned. So, the micro-cycle started again from the beginning.

Public building agency

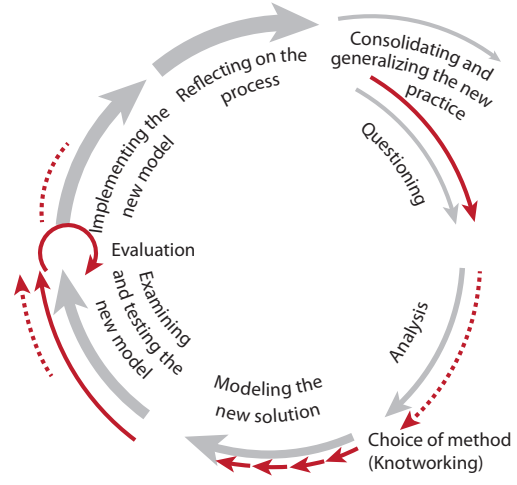

Construction company
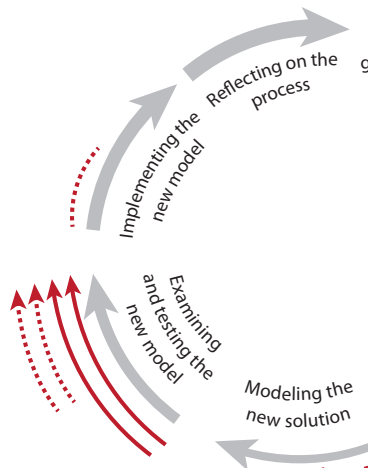
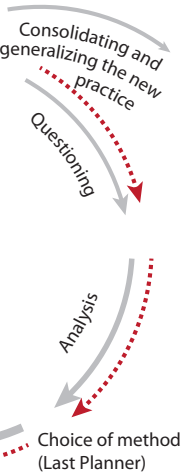

Engineering office

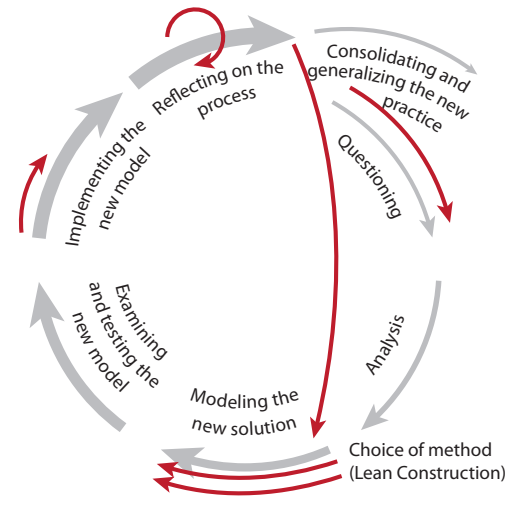

Figure 5. The micro-cycles of adoption process of LPS in the public building agency, the construction company and the engineering office.

\section{DISCUSSION}

This research depicts the adoption process of LPS as a part of an organisation's learning and developmental activities. The findings support the arguments of Arayici et al (2011) about the learning processes being complex. Some projects proceeded during this research, but some were still at the starting point after over two years of observation. The process complexity seemed to relate to lack of resources, lack of tools or different roles in the construction projects.

Over the years several researchers have reported the benefits of LPS in construction (Ballard \& Howell 1994; Priven et al. 2016; Tillman et al. 2016). The organisations were familiar with the benefits. So, adopting LPS was an easy solution to solve the problems in their current activities. In spite of the expected benefits, the adoption processes did not proceed easily. As FernandezSolis et al. (2013) has reported, the managers leading adoption processes face resistance from their partners and lack of support from their organisations. New procedures can be experienced as a threat and therefore they might face open or silent opposition, questioning and critique 
(Kerosuo \& Engeström 2003). In this study some partners complained about LPS sessions as they regarded them as waste of time. The employees also complained about the fact that they have not been heard in the planning of the learning process. They criticized the adoption process, not LPS itself. Based on this study, it is not the question whether the benefits are real and known, but how the adoption processes are managed.

Development projects in construction have traditionally been executed as top-down processes. This management model, however, is not always the best in motivating people for change (Chioccio et al. 2011; Arayci et al. 2011). In this study, there are examples of both top-down, bottom-up and combination approaches. The engineering office represented the top-down approach, the construction company the opposite. The public building agency represented the combination of approaches. Its management had a strong role in supporting the adoption process, but the site manager took the responsibility for the practical adaptation and sharing his knowledge to other personnel. Based on this study, the combination of the approaches seems to achieve the best results. Perez has stated the fragmented leadership as a hindrance to the adoption of LPS. According to this study, the combination management approach does not necessary lead to fragmented management, which was concerned as hindrance by Perez and Ghosh (2018).

A new object of activity usually emerges in the development of activity. The object of activity expanded across the boundaries of individual tasks and enabled the project participants to connect to the overall object of a project. In particular, it became apparent in the case of the public building agency. At the beginning of the process, each subcontractor was planning and optimizing one's own schedule in a building project. As the experiment proceeded, they started to plan schedule together with other subcontractors. The object of scheduling activity expanded by adopting LPS.

The theory of expansive learning and its learning actions (Engeström and Sannino 2010) worked as an analytical tool to depict the phases of the adoption processes. The cycle of expansive learning helped the researchers and the practitioners to understand how the processes proceeded, and how the processes and learning in the processes could be supported.

\section{CONCLUSIONS}

This study examines the adoption process of a new working method, LPS, as a part of an organisation's learning and developmental activities. Based on the findings of the study discussed in the previous section, the following conclusions can be drawn. First, the adoption of LPS being a complex process, the results of the process do not depend on the LPS method itself, but how the adoption processes are organised. Therefore, the planning, organising and resourcing of adoption processes should be the main concern of the organization when aiming to adopt LPS. Second, LPS expands objects of participant's activities and provides a wider understanding to the whole project. It also improves both managing one's own work and collaboration with other project partners.

The main contributions of the study are linked to the steps of an adoption process and how they can be modelled by using the epistemic learning actions of the theory of expansive learning. Another contribution is to find the mechanisms that indicate their success or failure in their establishment.

Solving historically and societally-based contradictions, manifested as questioning, resistance or breakthrough of new ideas on the operational level, is a typical starting point to the process of expansive organisational learning. In this study, the questioning of the current activities or an idea of a new more efficient activity (e.g. shorter the construction time) served as a first epistemic 
learning action on the operational level of organisations. The adoption processes of LPS in three different organisations were followed step by step for 2.5 years. The trajectories of the learning processes moving between the organizational and operational levels were depicted in each case. The participating organizations considered the analysis of the epistemic learning actions one of the most interesting results in the project. It offered them a conceptual framework to consider proceeding and the nature of adoption processes.

Another contribution of the study is the identified mechanisms that indicate success or failure in organization of adoption processes. The mechanisms indicating a successful adoption process are firstly, strong ownership of an adoption process, i.e. a strong role by the client or developmental personnel, secondly, enough time, resources and opportunities for learning together to use new tools in the practical project work and, thirdly, the combination of top-down and bottom-up approaches in the adoption process.

The limitation of the study was the length of the research project (2.5 years) which turned out to be far too short to thoroughly study the adoption of LPS in the organisations. More time would have been needed to study how LPS become established in the organisations. In addition, the relation of organisational level contradictions to operational level practices could be a useful task to future studies for improving the introduction of new methods and tools in construction industry.

\section{Acknowledgements}

The authors owe sincere thanks to the participating organizations, that allowed them to collect the data in their development projects. They also gratefully thank their colleagues for their help and insightful comments. The funding from the The Finnish Work Environment Fund is gratefully acknowledged. 


\section{References}

Adler, P. 2005. The evolving object of software development. Organization, 12(1), 401-435.

Anheim, F. 2003. Importance of the project team to the creation of learning within and between construction projects. Construction Process Improvement, 183-194

Arayici, Y., Coates, P., Koskela, L., Kaglioglou, M., Usher, C. \& O’Reilly, K. 2011. Technology adaption in the BIM implementation for lean architectural practice. Automation in Construction, 20, 189-195.

Ballard, G. \& Howell, G. 1994. "Implementing Lean Construction: Stabilizing Work Flow", Proceedings of the 2nd Annual Meeting of IGLC, 101-110.

Bertelsen, S. \& Koskela, L. 2005. “Approaches To Managing Complexity in Construction Project Production." International Conference on Complexity and the Built Environment, Liverpool, UK, 113.

Braun, V. \& Clarke, V. 2006. Using thematic analysis in psychology. Qualitative Research in Psychology, 3, 77-101.

Bresnen, M. 1990. Organizing construction: project organization and matrix management. London: Routledge.

Castillo, T., Alarcón, L.F. \& Salvatierra, J.L. 2016. “Last Planner System, Social Networks and Performance of Construction Projects" In: Proceedings of the 24th Annual Conference of IGLC, sect.6 pp. 43-52.

Chambers, E. 2000. Applied ethnography, in Denzin, N. K. and Lincoln, Y. S. (eds) Handbook of Qualitative Research, $2^{\text {nd }}$ edn, Sage Publications, Thousand Oaks, London and New Delhi, pp. 85169.

Chan, P., Cooper, R. \& Tzortzopoulos, P. 2005. Organizational learning: conceptual challenges from project perspective. Construction Management and Economics, 23(7), 747-756.

Chioccio, F., Forgues, D., Paradis, D. \& Iordanova, I. 2011. Teamwork in Integrated Design Projects: Understanding the Effects of Trust, Conflict, and Collaboration on Performance. Project Management Journal, 42, 78-91.

Corradi, G., Gherardi, S. \& Verzelloni, L. 2010. Through the practice lens: Where is the bandwagon of practice-based studies heading? Management Learning,41(3), 265-283.

Delamont, S. 2004. Ethnography and participant observation. In C. Seale, G. Gobo, J. F. Gubrium \& D. Silverman (Eds.), Qualitative Research Practice, 217-229. London, Thousand Oaks, New Delhi: Sage.

Easterby-Smith, M. \& Lyles, M. A. 2011. The evolving field of organizational learning and knowledge management. In M. Easterby-Smith \& M. A. Lyles (eds.), Handbook of Organizational Learning and Knowledge Management. 1-21. Chichester: John Wiley \& Sons.

Ellen, R. F. (ed.) 1984. Ethnographic research. A guide to general conduct. San Diego, CA: Academic Press.

Engeström, Y. 1987. Learning by expanding: An activity-theoretical approach to developmental research. Helsinki, Finland: Orienta-Konsultit.

Engeström, Y. 1995. Object, contradictions and collaboration in medical congnition: An activitytheoretical perspective. Artificial Intelligence in Medicine, 7, 395-412.

Engeström, Y., Kerosuo, H. \& Kajamaa, A. 2007. Beyond discontinuity: Expansive organizational learning remembered. Management Learning, 38(3), 319-336. 
Engeström, Y., Lompscher, J. \& Rückriem, G. (Eds.) 2005. Putting activity theory to work: Contributions from developmental work research. Berlin: Lehmanns Media.

Engeström, Y., Rantavuori, J., \& Kerosuo, H. 2013. Expansive learning in a library: Actions, cycles and deviations from instructional intentions. Vocations and Learning, 6, 81-106.

Engeström, Y \& Sannino, A. 2010. Studies of expansive learning: Foundations, findings and future challenges. Educational Research Review, Vol , 5 1-24.

Fernandez-Solis, J. L., Porwal, V., Lavy, S., Shafaat, A., Rybkowski, Z. K., Son, K. \& Lagoo, N. 2013. Survey of Motivations, Benefits, and Implementation Challenges of Last Planner System Users. Journal of Construction Engineering and Management. 139(4), 354 - 360.

Fetterman, D. M. 2010. Ethnography 3rd Ed. Los Angeles, London, New Delhi, Singapore, Washington DC: Sage.

Fiol, C. M. \& Lyles, M. a. 1985. Organizational learning. Academy of Management Review, 10(4), 803-813.

Gherardi, S., Nicolini, D. and Odella, F. 1998. 'Toward a social understanding of how people learn in organizations', Management Learning, Vol 29(3): Pp. 273- 297.

Kalsaas, T. 2012. The Last Planner System style of planning: its basis in learning theory. Journal of Engineering, Project, and Production Management, 2(2), 88-100.

Kerosuo, H. \& Engeström, Y. 2003. Boundary crossing and learning in creation of new work practice. Journal of Workplace Learning, 15(7-8), 345-351.

Kerosuo, H. 2006. Boundaries in Action. An Activity-theoretical Study of Development, Learning and Change in Health Care for Patients with Multiple and Chronic Illnesses. Helsinki: University Press.

Kokkonen, A. \& Alin, P. 2015. Practice-based learning in construction projects: a literature review. Construction Management and Economics, 33(7), 513-530.

Kolb, D. A. 1984. Experiential learning. Experience as a source of learning and development. Englewood Cliffs, New Jersey: Prentice Hall.

Koskela, L. J., Stratton, R. \& Koskenvesa, A. 2010. Last Planner and critical chain in construction management: comparative analysis. Proceedings of the 18th Annual Conference of IGLC, pp. 538547

Leont'ev, A. N. 1978. Activity, Consciousness and Personality, Englewood Cliffs, New Jersey: Prentice-Hall.

Marshall, N. \& Bresnen, M. 2013. Where's the action? Challenges of ethnographic research in construction. In S. Pink, D. Tutt, and A. Dainty (eds). Ethnographic Research in the Construction Industry, pp. 108-24. London and New York: Routledge, Taylor \& Francis Group.

Miettinen, R. 2000. The concept of experiential learning and John Dewey's theory of reflective thought and action. International Journal of Life-long Education, 19(1), 54-72.

Miettinen, R. Kerosuo, H. Korpela, J. Mäki, T. \& Paavola, S. 2012. An activity-theoretical approach to BIM-research. In G. Gudnason and Rimar Scherer (Eds.), eWork and eBusiness in Architecture, Engineering and Construction, 777-781. London, UK: Taylor \& Francis Group.

Miettinen, R., Samra-Fredericks, D. \& Yanow, D. 2009. Re-turn to practice: an introductory essay. Organization Studies, 30(12), 1309-1327.

Nicolini, D. (2012). Practice, theory, work \& organization: an introduction. Oxford: Oxford University Press. 
Perez, A. M. \& Ghosh S. 2018. Barriers faced b y new-adopter of Last Planner System $\AA$ : a case study. Engineering, Construction and Architectural Management. Vol 25 Issue 9. pp. 1110-1126.

Prencipe, A. \& Tell, F. 2001. Inter-project learning: processes and outcomes of knowledge codification in project-based firms. Research Policy, 30, 1373-1394.

Priven, V., and Sacks, R. 2015. Effects of the Last Planner System on Social Networks among Construction Trade Crews. Journal of Construction Engineering and Management Vol. 141, Issue 6.

Priven, V., and Sacks, R. 2016. Impacts of the Social Subcontract and Last Planner System Interventions on the Trade-Crew Workflows of Multistory Residential Construction Projects. Journal of Construction Engineering and Management Vol. 144, Issue 7.

Ragin, C. C. 1992. Introduction: Cases of "What is a case?" In C. C. Ragin \& H. S. Becker (eds.) What is a case? Exploring the foundations of social inquiry, pp. 1-17. Cambridge: Cambridge University Press.

Rapley, I. 2004. Interviews. In C. Seale, G. Gobo, J. F. Gubrium \& D. Silverman (eds.), Qualitative Research Practice, pp. 15-33. London, Thousand Oaks, New Delhi: Sage Publications.

Siriwardena, M. L. 2015. Organizational learning in construction. A framework for the process improvement. PhD Theses, School of Built Environment, College of Science and Technology, University of Salford, UK.

Swan, J., Scarbrough, H. \& Newell, S. 2010. Why don't (or do) organizations learn from projects? Management Learning, 41(3), 325-344.

Tillmann, P., Sargent, Z. 2016. “Last Planner \& Bim Integration: Lessons From a Continuous Improvement Effort." In: Proceedings of the 24th Annual Conference of IGLC, sect. 6 pp. 113122

Van Maanen, John. 1988. Tales of the field: on writing ethnography. Chicago: University of Chicago Press

Whyte, J. \& Lobo, S. 2010. Coordination and control in project-based work: Digital objects and infrastructures for delivery. Construction Management $\S$ Economics, 28(6), 557-567

Wenger, E. 1998. Communities of practice, meaning and identity. Cambridge, UK: Cambridge University Press.

Young, M. 2001. Contextualising a new approach to learning: some comments on Yrjö Engeström's theory of expansive learning. Journal of Education and Work, 14(1), 157-161.

\section{Figure legends}

Figure 1. The sequence of learning actions in an expansive learning cycle (adapted from Engeström \& Sannino 2010, 8)

Figure 2. Time line of the LPS adoption process in the public building agency.

Figure 3. Time line of the LPS adoption process in the construction company.

Figure 4. Time line of the LPS adoption process in the engineering office.

Figure 5. The micro-cycles of adoption of LPS in the public building agency, the construction company and the engineering office. 